\title{
Research
}

\section{Climate Variability Reveals Complex Events for Tularemia Dynamics in Man and Mammals}

\author{
$\underline{\text { Thomas R. Palo }}^{1}$, Clas Ahlm${ }^{2}$, and $\underline{\text { Arne Tärnvik }}^{2}$
}

\begin{abstract}
Tularemia is caused by the bacterium Francisella tularensis, but the natural reservoir is unknown and environmental conditions for outbreaks in mammals and man are poorly understood. The present study analyzed the synchrony between the North Atlantic Oscillation (NAO) index, the number of human cases of tularemia reported in Sweden, and the density of hares. Climate variation at a lag of $2 \mathrm{yr}$ explained as a single factor $\sim 27 \%$ of the variation in the number of tularemia cases over time. A low NAO index, indicating cold winters, and low water flow in rivers during the coming summer were associated with high numbers of human cases of tularemia 2 yr later. The number of mountain hares was not related to NAO or to the number of cases of tularemia. The change in mountain hare numbers was negatively associated with the number of human cases, showing the sensitivity of this species to the disease. Low turnover in water environments may at some point in time trigger a chain of events leading to increased replication of $F$. tularensis via unknown reservoirs and/or vectors that affect humans and mammals. A possible increase in the NAO index with a future warmer climate would not be expected to facilitate a higher frequency of tularemia outbreaks in Sweden.
\end{abstract}

Key Words: tularemia; climate; North Atlantic Oscillation index; disease transmission; global warming; Francisella tularensis; Lepus timidus

\section{INTRODUCTION}

To reveal a possible dependence of the epidemiology of zoonotic diseases on climate variability, long time series extending over several decades are required. In Sweden, epidemiological data on several zoonotic diseases and hunting statistics are available for $60 \mathrm{yr}$ or more. Likewise, data on climate variation are available for the whole 20th century (Hurrell 1995). Few studies have analyzed the influence of climate change on the epidemiology of diseases caused by environmental microbial agents (but see Lindsay and Birley 1996, Schmaljohn and Hjelle 1997, Engenthaler et al. 1999).

The global warming of the northern latitudes is expected to increase, especially winter temperatures (Post and Stenseth 1999). The North Atlantic Oscilliation (NAO) is a large-scale climatic variation that determines weather patterns over
Europe (Hurrell 1995). The NAO is positively related to temperature, and a high NAO index corresponds to mild winters over Scandinavia, whereas a low index results in cold winters. The NAO shows variability over time and could serve as a tool for analyzing the sensitivity of various living organisms to climate changes (Post and Forchammer 2001).

Tularemia is a zoonotic disease caused by the intracellular bacterium Francisella tularensis, which appears to have two main subspecies. F. tularensis spp. tularensis is restricted to North America, whereas $F$. tularensis spp. holarctica occurs in both North America and Eurasia. The latter causes disease in rodents and lagomorphs and is spread to humans by direct contact with infected animals, arthropod bites, inhalation of contaminated dust, or the oral intake of contaminated water or food (Tärnvik et al. 2004). 
Outbreaks of tularemia occur at highly irregular intervals in various parts of Europe, most frequently in Finland and Sweden. The reservoir of $F$. tularensis in nature is unknown. Mammals are not believed to harbor the organism between outbreaks and are regarded as victims on the same footing as man (Mörner 1992). Experimental work on animal models shows that rodents and other mammals either succumb to the infection or effectively eradicate it. Arthropod vectors are not believed to serve as a reservoir either, although several arthropods seem capable of transmitting the disease. In areas in which ticks are prevalent, they can trasmit tularemia (Hubalek et al. 1996), whereas, in areas free from ticks, the disease may be transmitted by mosquitos (Ohlin 1942, Eliasson et al. 2002). It is possible that arthropod vectors transmit the bacteria by passive transfer rather than by a stage that involves intravector replication.

The occurrence of tularemia in some geographical areas at intervals of several years or even decades suggests that the bacteria may be spread more widely in nature than is apparent from their occurrence in mammals. It is speculated that $F$. tularensis may exist during the intervals between epidemic outbreaks at a low density in an environmental niche that is sensitive to stochastic climate events. It could be assumed that, in certain climatic situations, conditions that favor the replication of $F$. tularensis may allow the pathogen to reach densities sufficient to cause an outbreak in mammals and man. Based on such a scenario of climate change, we found it worthwhile to focus on a possible relation between climate indices, hares, and the incidence of tularemia in man.

Ever since the ecology of tularemia was first studied, small mammals and arthropod vectors have been considered possible reservoirs of $F$. tularensis (Hopla 1974). According to this hypothesis, the population density of small mammals ought to be an important factor in transmission. It was expected that high densities of the mammals implicated, such as the mountain hare, would be associated with outbreaks. Moreover, because tularemia is lethal to hares, these outbreaks would be followed by a decline in, or even the collapse of, the hare population. However, based on more recent evidence from work on animal models, the reservoir function of mammals has been questioned. When they survive tularemia, mammals usually eradicate the bacteria and develop a strong protective immunity (Törnvik et al. 2004). There is little evidence to suggest that mammals are capable of sustaining the infection over time periods free from tularemia outbreaks. Therefore, alternative mechanisms behind fluctuations in the occurrence of tularemia need to be considered. Because tularemia is associated with water environments, stochastic events such as weather may affect these environments directly or indirectly. Large-scale climatic patterns such as the NAO are important determinants of the Scandinavian weather situation, including temperature and precipitation.

We propose that low runoff from the watersheds of major rivers or temporary water bodies after major flooding events may create environments that are favorable for the replication of $F$. tularensis. If so, the amount of time required for the population buildup of $F$. tularensis would determine the time of the subsequent outbreak. We conducted an analysis of long time series extending over $60 \mathrm{yr}$ to test this hypothesis and to identify the factors that drive tularemia outbreaks.

\section{METHODS}

Time series were selected based on two criteria: the length of the series, which extends over decades, and mammalian species associated with tularemia. Data on mountain hare (Lepus timidus) comprised hunting statistics from the Swedish Hunting Association for the years 1939-2000. It has been shown that hunting data, despite variations in hunting efficiency, provide a good estimate of the actual population density (Cattadori et al. 1999, Haydon et al. 2002). Data on the yearly mean of tularemia cases for the years 1930-2003 were obtained from the Swedish Institute for Infectious Disease Control, Stockholm, Sweden.

We used the mean North Atlantic Oscillation (NAO) index for the winter months of December, January, February, and March as a proxy for climate during these time periods. Data for monthly NAO indices were taken from http://www.cgd.ucar.edu/. Data on water flow in the Angerman River were obtained from Bergström (1999) and the Swedish Meterological and Hydrological Institute.

Tularemia data were transformed by $\operatorname{Ln}($ tula +1$)$ and hare data by $\operatorname{Ln}$ (mountain hare) to make the variance independent of the mean. In the analysis, we used multivariate linear regressions with bestmodel selection based on Aikakes Information 
Criteria (AIC) performed in $\mathrm{R}$. We tested for autocorrelation between significant variables. The first regression model was $\operatorname{Ln}($ tula +1$)$ against year. The residuals from this regression were used for the multivariate model:

Residtu $_{\mathrm{t}}=\mathrm{b}_{0}+\mathrm{b} 1(m h)_{\mathrm{t}}+\mathrm{b}_{2}(\Delta m h)_{\mathrm{t}}+\mathrm{b}_{3}(\mathrm{NAO})_{\mathrm{t}-1}+$ $\mathrm{b}_{4}\left(\mathrm{NAO}_{\mathrm{t}-2}\right)+\mathrm{b}_{5}\left(\mathrm{NAO}_{\mathrm{t}-3}\right)+\mathrm{b}_{6}\left(\right.$ wflow $\left._{\mathrm{t}-1}\right)(1)$

where Residtu $=$ residuals, $m h=\mathrm{Ln}$ (mountain hare), $\Delta m h=\mathrm{Ln}$ (change in mountain hare), wflow = yearly mean maximum water flow, $t$ denotes time, and $b_{0}-$ $\mathrm{b}_{6}$ are constants.

\section{RESULTS}

As seen in Fig. 1, an increase in the number of tularemia cases with year occurred from 1930 to 2000 (linear regression $Y=0.033 \mathrm{X}$ - 61,56; Fisher`s $F=11,36 ; p<0.001)$. We took this time trend into account by using the residuals from the linear regression of number of cases vs. time as a dependent variable in the model analysis.

The full general linear multivariate model that included residuals of tularemia as a dependent variable, the number of mountain hares, change in mountain hare numbers, North Atlantic Oscillation (NAO) index in the current year and at different lags, and water flow was significant (ANOVA, $F=$ 6.556, $P<0.0001, r^{2}=0.31$, Aikakes Information Criteria $=229.677)$. The best significant model included four variables: NAO index at negative lags of 1 and $2 \mathrm{yr}$, water flow and change in hare numbers $\left(r^{2}=0.32, F=4,42, p>0.004, \mathrm{df}=4, \mathrm{AIC}=226.71\right)$. The most parsimonious model that explained variation in tularemia cases with the least amount of variables included NAO at negative lag of 1-2 yr and water flow. The final model writes:

$$
\text { residtula }=-2.725-0.661 * \mathrm{NAO}_{\mathrm{t}-1}-0,401 * \mathrm{NAO}_{\mathrm{t}-2}+
$$
$1.333 * 10^{-03 *}$ wflow $_{\mathrm{t}-1}(2)$

$\left(r^{2}=0.27, F=8.33, p<0.0001\right.$, AIC $\left.=226.50\right)$. Only $3.3 \%$ of the residuals from the model were out of the 1.95 range, suggesting a nearly normal distribution of the data. Cross-correlation coefficients between variation in human tularemia cases and the NAO index confirmed negative lags at 1-2 yr. The strongest influence on the model was water flow $(t=3.396, p<0.001)$ and NAO indexes at lags of 1 and $2 \mathrm{yr}(p<0.001$ and $p<0.024)$, which was negatively correlated with the number of tularemia cases. Figure 2 shows the smoothed relationship of the 5-yr mean number of tularemia cases and the 5-yr mean NAO index. A linear regression between numbers of tularemia cases and change in mountain hare numbers was nonsignificant and did not contribute to the final model.

The NAO index might be assumed to be linked to physical processes such as runoff in major rivers. The water flow in a major river within the endemic tularemia area in Sweden was significantly and positively correlated with the NAO index for the year before the outbreak and also contributed significantly to the multivatiate model. As seen in Fig. 3, the linear model for the relationship between water flow and NAO writes:

$$
\begin{aligned}
& \text { wflow }=1898+208 * \mathrm{NAO}_{\mathrm{t}-1}(3) \\
& (F=13.01, p<0.001, \mathrm{df}=1) .
\end{aligned}
$$

\section{DISCUSSION}

Our results suggest that climate variability may be one possible explanation for the irregular annual occurrence of tularemia outbreaks in man and mountain hare. In particular, cold weather in the winter season in year 1 and a subsequent low water flow in rivers in the summer seem to be determinants for an outbreak in the summer of year 2. This $2-y r$ lag would allow a complex chain of ecological events to occur, eventually resulting in conditions optimal for the replication of Francisella tularensis in a water environment.

The present multivariate regression model showed a negative relationship over time between the number of cases of tularemia in humans and the density of hares. This result confirms the assumption that hares do not serve a reservoir function and would be expected to decline in density when the number of human cases increases. Hares are extremely susceptible to $F$. tularensis and die within days of being infected (Borg et al. 1969). According to our data, the mountain hare does not seem to influence tularemia dynamics in man. Most likely, the hare is a victim of tularemia, just like , although much more vulnerable than, man. 
Fig. 1. Variation in the number of tularemia cases in Sweden. Data are $\operatorname{Ln}(x+1)$ transformed.

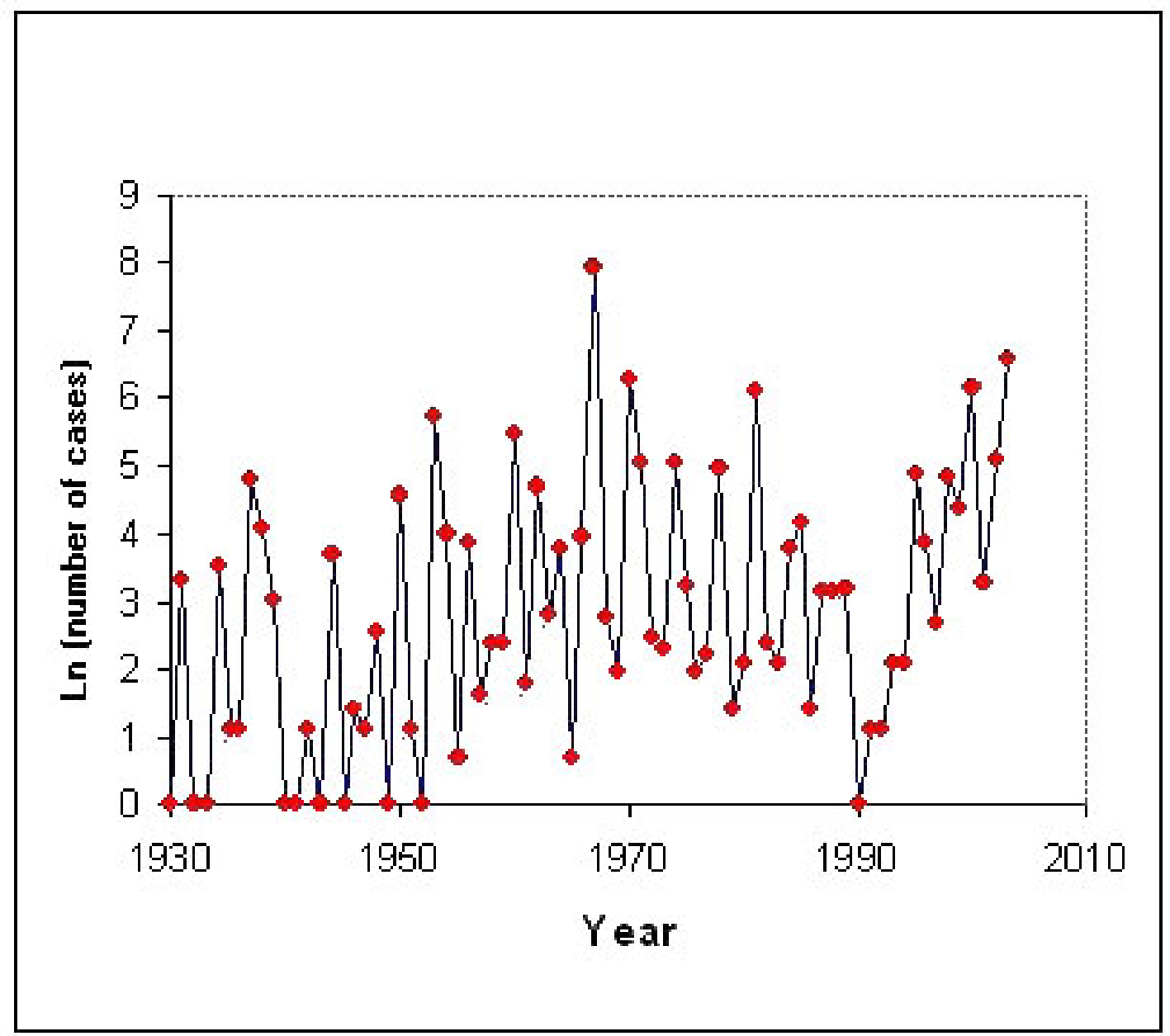

In the absence of a known reservoir of $F$. tularensis, it is currently speculated that the bacteria might reside in some water-dwelling unicellular eukaryote (Gustafsson 1989, Berdal et al. 1996, Abd et al. 2003). F. tularensis belongs to the facultative intracellular pathogens that replicate in an intracellular environment in the infected mammalian host, and a reservoir in nature would be expected to be a eukaryotic cell. Another facultative intracellular pathogen that is found in water environments is Legionella pneumophila. This pathogen causes a host response in mammals and man quite similar to that of $F$. tularensis (Fields 1996). When dwelling in their moist habitat, legionellae use the intracellular environment of amoebae for replication. Given the relationship of tularemia to climate variability and water flow in rivers, a search for a possible reservoir of $F$. tularensis spp. holarctica in natural water environments might be worthwhile.

The association of tularemia with natural water has been confirmed by the extensive and numerous epidemics that have occurred in the former Soviet Union, Kazakhstan, Turkey, Spain, and the Balkans (see Pollitzer 1967, Helvaci et al. 2000, Anda et al. 2001, Reintjes et al. 2002). In Sweden, tularemia outbreaks occur frequently along the rivers in the central part of the country. F. tularensis is known to survive in water and mud for months (Parker et al. 
Fig. 2. Tularemia and the North Atlantic Oscillation (NAO) index. Five-year smoothed mean of the winter NAO index and log number of human tularemia cases in Sweden for the years 1931-2002. Linear regression equation: $Y=1.617-0.458 x\left(r^{2}=0.25, F=21.63, p<0.001\right)$. Red dots represent observations, solid black lines represent predictions, dotted lines show a $95 \%$ confidence limit for predictions, and solid gray lines show a $95 \%$ limit for the mean.

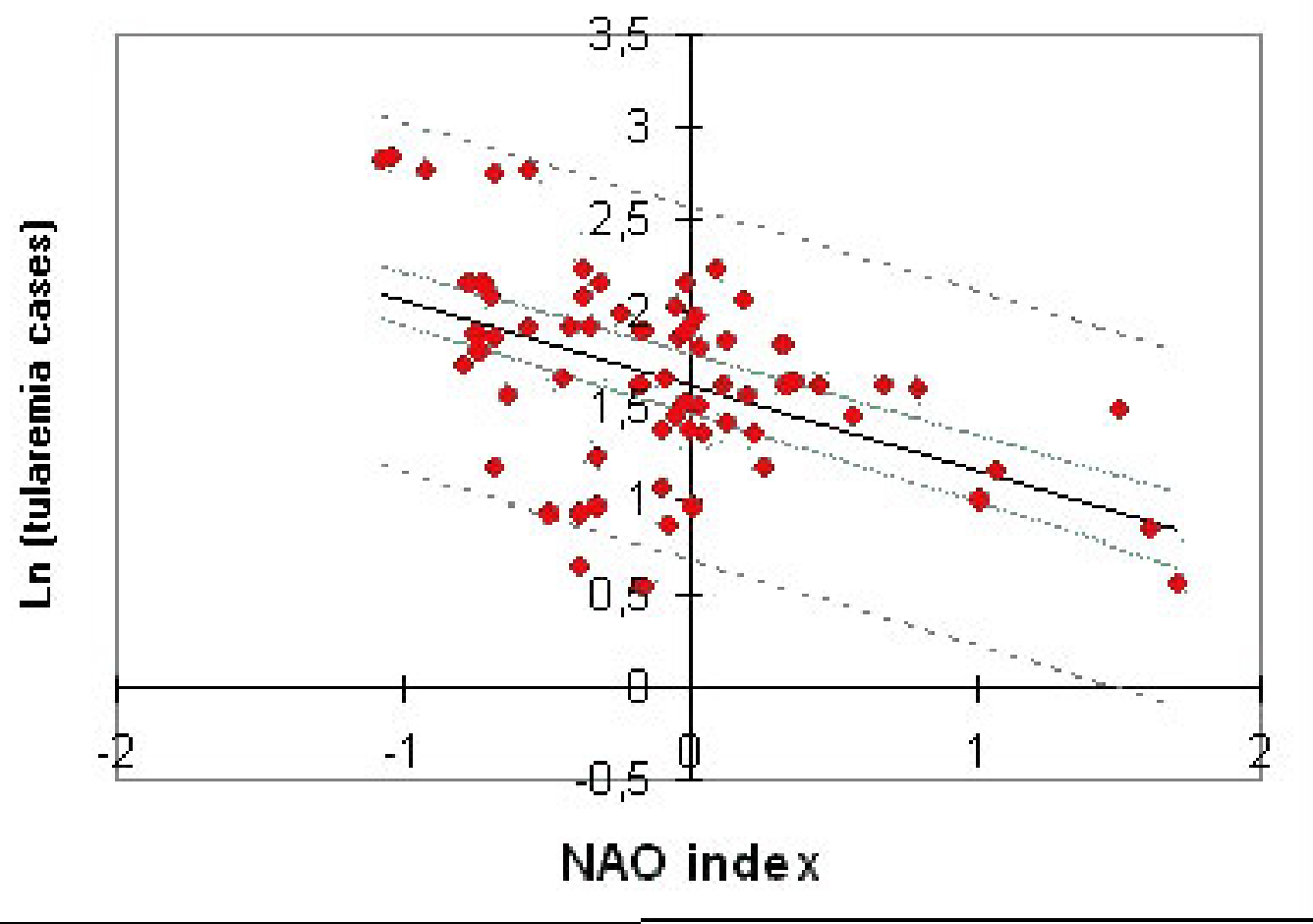

1951, Hopla 1974). In a large survey of mammals, beaver showed a high percentage of antibodies to $F$. tularensis, indicating a heavy exposure to the agent in its environment (Jellison et al. 1942, Mörner and Sandstedt 1983). Thus, several pieces of circumstantial evidence support a current hypothesis that the reservoir of $F$. tularensis spp. holarctica may be found in a water environment, apart from both mammals and arthropod vectors.

A climate factor may allow temporary water bodies to support the initiation of a burst of replication, leading to a bacterial density sufficient to cause spread to mammals and humans. For example, cold winters may afford suitable preconditions because of their association with less precipitation. A relative drought may affect the runoff in watershed areas and decrease the amount of circulation in water bodies. This might provide good temporary conditions for the growth of protozooans in still waters and a subsequent buildup of arthropod vector populations such as mosquitos. Warmer winters would result in the reverse situation, i.e., enhanced runoff that increases the circulation in water bodies and provides a less favorable environment for $F$. tularensis in its reservoir. Such a complex relationship would be expected to exhibit time lags between trigger and response, as observed in this study.

In conclusion, this paper demonstrates that there is a meaningful relationship between climate and the number of human cases of tularemia. Based on our findings, it might be argued that the higher temperatures associated with global warming would not be expected to facilitate an increased occurrence 
Fig. 3. Water flow in the Ångerman river in relation to the previous winter's North Atlantic Oscillation index. Linear regression equation: $Y=1898.4+208.01 x, r^{2}=0.183, F=13.01, p<0.001$. Red dots represent observations, solid black lines represent predictions, dotted lines show a $95 \%$ confidence limit for predictions, and solid gray lines show a $95 \%$ limit for the mean.

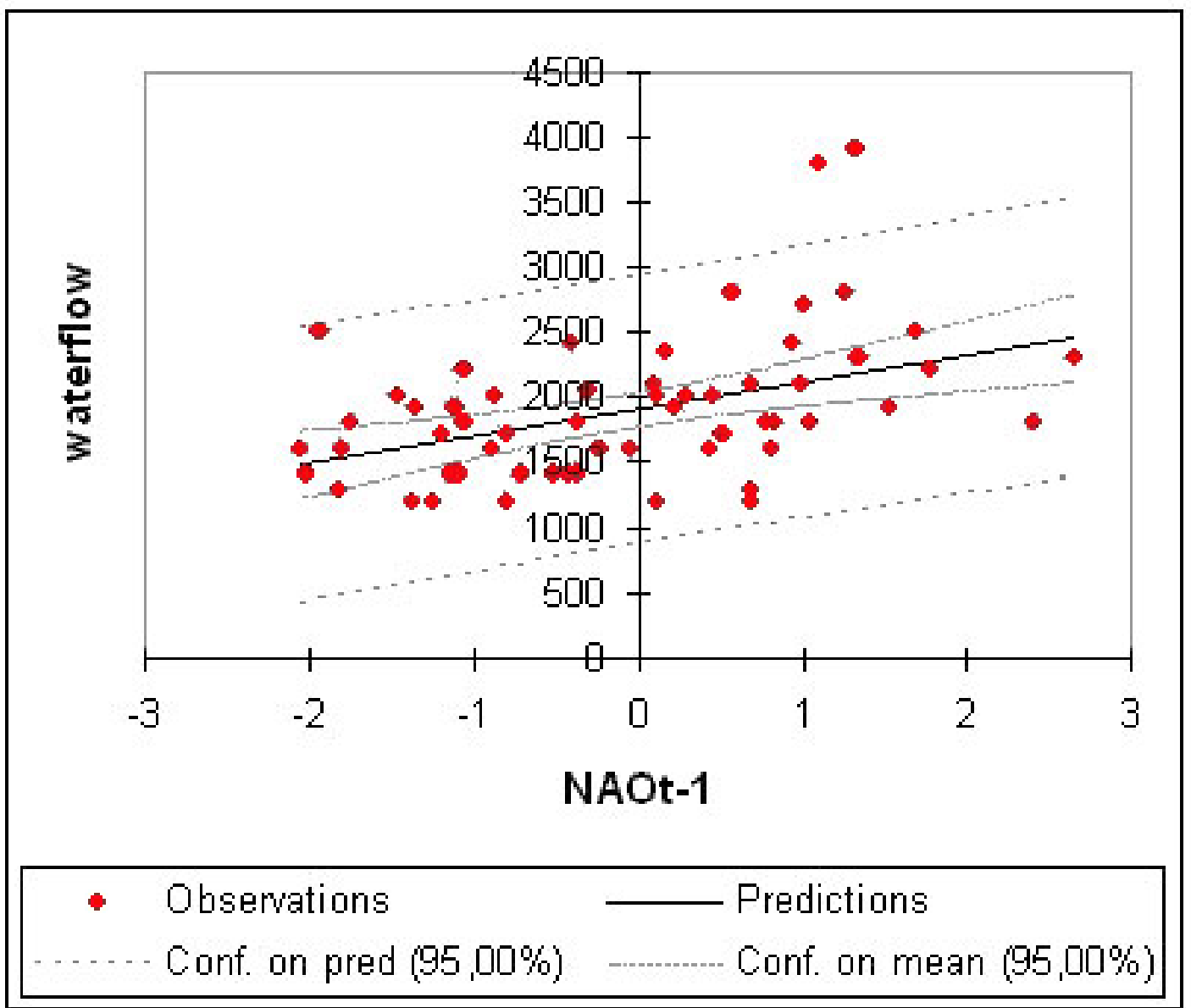

of outbreaks of tularemia in Sweden.

Responses to this article can be read online at: http://www.ecologyandsociety.org/vollo/iss1/art22/responses/

\section{Acknowledgments:}

We thank Jonas Kindberg at the Swedish Hunting Association for kindly providing the mountain hare data. Nils Ekelund and Bengt-Gunnar Jonsson made comments on an early draft of the manuscript. Thanks are extended to Neil White, who assisted with the statistical analyses.

\section{LITERATURE CITED}

Abd, H., T. Johansson, I. Golovliov, G. Sandström, and M. Forsman. 2003. Survival and growth of Francisella tularensis in Acanthamoeba 
castellanii. Applied Environmental Microbiology 69:600-606.

Anda, P., J. Segura del Pozo, J. M. Díaz García, R. Escudero, F. J. García Peña, M. C. López Velasco, R. E. Sellek, M. R. Jiménez Chillarón, L. P. Sánchez Serrano, and J. F. Martínez Navarro. 2001. Waterborne outbreak of tularemia associated with crayfish fishing. Emerging Infectious Disases 7(3), Supplement:575-582. Also available online at

http://www.cdc.gov/ncidod/eid/vol7no3 supp/anda. $\underline{\mathrm{htm}}$.

Berdal, B. P., R. Mehl, N. K. Meidell, A. M. Lorentzen-Styr, and O. Scheel. 1996. Field investigations of tularemia in Norway. FEMS Immunology and Medicinal Microbioloy 13:191-195.

Bergström, S. 1999. Häga vattenfläden i reglerade älvar. Fakta nr 1. Swedish Meteorological and Hydrological Institute, Norrköping, Sweden.

Borg, K., E. Hanko, T. Krunajevic, N.-G. Nilsson, and P. O. Nilsson. 1969. On tularemia in the varying hare (Lepus timidus L.). Nordic VeterinaryMedicine 21:95-104.

Cattadori, I. M., P. J. Hudson, S. Merler, and A. Rizzoli. 1999. Synchrony, scale and temporal dynamics of Rock patridge (Alectoris gracea saxatilis) populations in the Dolomites. Journal of Animal Ecology 68:540-549.

Eliasson, H., J. Lindbäck, J. P. Nuorti, M. Arneborn, J. Giesecke, and A. Tegnell. 2002. The 2000 tularemia outbreak: a case-control study of risk factors in disease-endemic and emergent areas, Sweden. Emerging Infectious Disases 8:956-960.

Engelthaler, D. M., D. G. Mosley, J. E. Cheek, C. E. Levy, K. K. Komatsu, P. Ettestad, T. Davis, D. T. Tanda, L. Miller, J. W. Frampton, R. Porter, and R. T. Bryan. 1999. Climatic and environmental patterns associated with hantavirus. Emerging Infectious Disases 5:87-94.

Fields, B. S. 1996. The molecular ecology of legionellae. Trends in Microbiology 4:286-290.

Gustafsson, K. 1989. Growth and survival of 4 strains of Francisella tularensis in a rich medium preconditioned with Acanthamoeba palestinensis. Canadian Journal of Microbiology 35:1100-1104.
Haydon, D. T., D. J. Shaw, I. M. Cattadori, P. J. Hudson, and S. J. Thirgood. 2002. Analysing noisy time series: describing regional variation in the cyclic dynamics of red grouse. Proceedings of the Royal Society of London B 269:1609-1617.

Helvaci, S., S. Gedikoglu, H. Akalin, and H. B. Oral. 2000. Tularemia in Bursa, Turkey: 205 cases in 10 years. European Journal of Epidemiology 16:271-276.

Hopla, C. 1974. The ecology of tularemia. Advanced Veterinary Science and Comparative Medicine 18:25-53.

Hubalek, Z., F. Treml, J. Halouzka, Z. Juricova, M. Hunady, and V. Janik. 1997. Frequent isolation of Francisella tularensis from Dermacentor reticulatus ticks collected in adjacent areas of the Czech and Austrian Republics. Central European Journal of Public Health 5:199-201.

Hurrell, J. W. 1995. Decadal trends in the North Atlantic Oscilliation: regional temperatures and precipitation. Science 269:676-679.

Jellison, W., G. M. Kohls, W. J. Butler, and J. A. Weaver. 1942. Epizootic tularemia in the beaver, Castor canadensis, and the contamination of stream water with Francisella tularensis. American Journal of Hygiene 36:168-182.

Lindsay, S. W., and M. H. Birley. 1996. Climate change and malaria transmission. Annals of Tropical Medicine and Parasitology 90:573-588.

Mörner, T. 1992. The ecology of tularemia. Review of Science and Technology11(4):1123-1130.

Mörner, T., and K. Sandstedt. 1983. A serological survey of antibodies against Franciscella tularensis in some Swedish mammals. Nordisk Veterinaer Medicin 35:82-85.

Ohlin, G. 2002. Occurrence and mode of transmission of tularemia in Sweden. Acta Microbiologica Scandinavica 19:220-247.

Parker, R., E. Steginhaus, G. Kohls, and W. Jellison. 1951. Contamination of natural waters and mud with Pasteurella tularensis and tularemia in beavers and muskrats in the northwestern United States. National Institute of Health Bulletin 
193:1-61.

Pollitzer, R. 1967. History and incidence of tularemia in the Soviet Union: a review. Institute of Contemporary Russian Studies, Fordham University, New York, New York, USA.

Post, E., and M. Forchhammer. 2001. Pervasive influence of large-scale climate in the dynamic of a terrestrial vertebrate community. BMC Ecology 1:5.

Post, E., and N. C. Stenseth. 1999. Climate variability, plant phenology and northern ungulates. Ecology 80:1322-1339.

Reintjes, R., I. Dedushaj, A. Gjini, T. R. Jorgensen, B. Cotter, A. Lieftucht, F. D'Ancona, D. T. Dennis, M. A. Kosoy, G. Mulliqi-Osmani, R. Grunow, and A. Kalaveshi. 2002. Tularemia outbreak investigation in Kosovo: case control and environmental studies. Emerging Infectious Diseases 8(1):69-73.

Schmaljohn, C., and B. Hjelle. 1997. Hantaviruses: a global disease problem. Emerging Infectious Diseases 3:95-104.

Tärnvik, A., H.-S. Priebe, and R. Grunow. 2004. Tularemia in Europe: an epidemiological overview. Scandinavian Journal of Infectious Diseases 36:350-355. 